\title{
Retraction Note: Land ecological evaluation based on genetic network algorithm and real-time data monitoring of cloud computing system
}

\author{
Zhou Yanyan $^{1}$
}

Published online: 6 December 2021

C) Saudi Society for Geosciences 2021

Retraction Note: Arabian Journal of Geosciences (2021) 14: 1572

https://doi.org/10.1007/s12517-021-07973-9

The Editor-in-Chief and the Publisher have retracted this article because the content of this article is nonsensical. The peer review process was not carried out in accordance with the Publisher's peer review policy. The author has not responded to correspondence regarding this retraction.

The original article can be found online at https://doi.org/10.1007/ s12517-021-07973-9

Zhou Yanyan

zhou89y@126.com

1 School of Mathematics and Computer, Tongling University, Tongling 244000, Anhui, China 